Article

\title{
Initial Provincial Water Rights Dynamic Projection Pursuit Allocation Based on the Most Stringent Water Resources Management: A Case Study of Taihu Basin, China
}

\author{
Min $\mathrm{Ge}^{1,2, *}$, Feng-Ping $\mathrm{Wu}^{3}$ and Min You ${ }^{3}$ \\ 1 School of Business Administration, Hohai University, Changzhou 213022, China \\ 2 School of Business, Jiangsu University of Technology, Changzhou 213013, China \\ 3 School of Business, Hohai University, Nanjing 211100, China; wfp@hhu.edu.cn (F.-P.W.); \\ youmin@126.com (M.Y.) \\ * Correspondence: ge_min19@126.com; Tel.: +86-519-8697-8206
}

Academic Editors: Helena Margarida Ramos and Davide Viaggi

Received: 24 August 2016; Accepted: 3 January 2017; Published: 10 January 2017

\begin{abstract}
Clarification of initial water rights is the basis and prerequisite for a water rights trade-off market and also an effective solution to the problem of water scarcity and water conflicts. According to the new requirements for the most stringent water resources management in China, an initial provincial water rights allocation model is proposed. Firstly, based on analysis of multiple principles for initial provincial water rights allocation including total water use, water use efficiency, water quality of water function zones, regional coordination and sharing, an index system of initial provincial water rights allocation is designed. Secondly, according to dynamic projection pursuit technique, an initial provincial water rights allocation model with the total water use control is set up. Moreover, the self-adaptive chaotic optimization algorithm is applied to tackle the model. Finally, a case study of Taihu Basin is adopted. Considering the multiple scenarios of three different water frequencies $(50 \%, 75 \%$ and $90 \%$ ) and planning year 2030, the empirical results show Jiangsu Province always obtains the most initial water rights. When the developing situation of provinces are given more consideration, Shanghai should acquire more initial water rights than Zhejiang Province; but when the dynamic increment evolving trend of provinces is taken more into account, Shanghai should obtain less initial water rights than Zhejiang Province. The case about Taihu Lake further verifies the feasibility and effectiveness of the proposed model and provides a multiple-scenarios decision making support for entitling the initial water rights with the most stringent water resources management constrains in Taihu Basin.
\end{abstract}

Keywords: most stringent water resources management; initial provincial water rights; dynamic projection pursuit

\section{Introduction}

China is facing a great challenge as water is still a major constraint on the nation's economic and social development due to the growing population, urbanization, and industrialization at a time when there are serious water shortages, growing pollution, severity of droughts, and declining aquatic ecosystems. Although China is rich in water resources and ranks sixth in the world in terms of water volume, the available water in China is only $1998.6 \mathrm{~m}^{3}$ per capita in 2014 and less than one-quarter of the world average which can be shown by the data from China Statistical Yearbook (2015). China's amount of water use reached 609.5 billion $\mathrm{m}^{3}$ (Figure 1) in 2014. However, the annual 
water scarcity across the country has exceeded 50 billion $\mathrm{m}^{3}$ on average according to the data from Global Water Partnership.

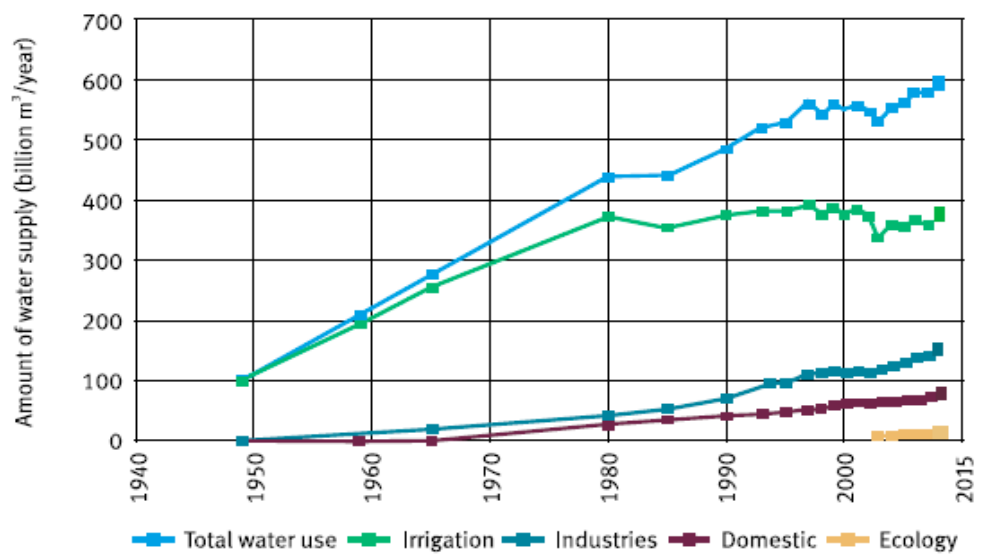

Figure 1. Increasing water use in China. Data source: China Water Resources Bulletin (1997-2000) and China Statistical Yearbook (2000-2015).

With China's previous water resources management system, the cost of using water was nearly zero which caused a similar external diseconomy of "tragedy of the commons". In that situation, injudicious development and overuse of water cannot be avoided and the negative impacts on environment came out including rivers drying up, ecosystem degradation, and environment deterioration.

At present, under the new scenarios of the most stringent water resources management system, in order to address these water problems, China is establishing a legal framework including initial water rights, water licensing, and a water rights trade-off to reform water allocation mechanisms and property rights systems to fit more closely with China's developing and maturing market economy. In fact, the final distribution of wealth, however, does depend on how property rights are initially assigned. Just as the Coase Theorem presented, the initial allocation of property rights often matters for efficiency due to transaction costs cannot be neglected [1]. Therefore, assignment of initial water rights is particularly important for fairness of water use and water efficiency. Clarification of initial water rights in China is not only the basis and prerequisite for a water rights trade-off market but also an effective solution to the problem of water scarcity and water conflicts.

Initial provincial water rights are an important part of river basin initial water rights. Existing literature about initial provincial water rights optimal allocation is in pursuit of a more scientific and effective allocation plan. However, as the major reforms to the implementation of the new most stringent water resources management system in China, the existing theory and practice of provincial initial water rights allocation should meet the new requirements of this system. Therefore, how to assign a reasonable allocation of initial provincial water rights, following the benchmark of the new most stringent water resources management system, is not only the major element and core aspect of basin initial water rights allocation but also an important approach to enhancing the efficiency of water resources utilization and significant for achieving harmony between economic and social development and available water resources in China. Recently, initial provincial water rights optimal allocation has been an active research field both in foreign and domestic areas. A majority of literature in this area can be divided into four categories.

The first category focuses on using hybrid allocation method to solve the initial provincial water rights allocation problems. For instance, Wang Hao et al. [2] found water resources allocation in China should follow a "natural-artificial" dual knowledge and perception mode for modern river basin water cycling process. Wu Dan et al. [3] established the bi-level optimization model of the compound system for basin initial water rights allocation to realize the reasonable allocation of water rights in different regions and different industries. Considering the pollution limits of water functional zones, which is 
the one "red line" of the most stringent water resources management, Ge Min et al. [4] proposed a provincial initial water rights incentive allocation model with total pollutant discharge constraints.

The second category pays close attention to multi-participation allocation model. For instance, Ralph [5] set up a generalized simulation model called Water Right Analysis Package (WRAP) which was implemented in the state of Texas for the state's 23 river basins. Yan-ping Chen et al. [6] divided the regions of the same basin into a disadvantaged group and an advantaged group, based on which they founded an evolutionary game model. They also adjusted the water rights of different regions according to the evolutionary stable strategy. Read et al. [7] established the model of negotiation with multiple-decision makers over water rights allocation.

The third category concerns an allocation model of multi-objective optimization. For instance, Feng-ping $\mathrm{Wu}$ et al. [8] established a multi-objective and semi-structural fuzzy optimization model in order to solve the problem of initial allocation of water rights of the first hierarchy. Xian-feng Huang et al. [9] created a multi-objective chaotic optimization algorithm. Condon et al. [10] presents the development of a water allocation model (WAM) for an integrated physical hydrology model. His management model uses linear optimization to maximize satisfaction of demand.

The fourth category focuses on applying interactive or harmonious allocation method to tackle the initial provincial water rights allocation problems. For instance, Feng-ping Wu and Min Ge et al. [11] put forward principles for harmonious and disharmonious judgment of initial water rights allocation, and they also came up with an interactive method of initial water rights allocation which could fully assimilated the ideas of different apartments from different regions about the initial allocation of water rights. Furthermore, Wang et al. [12] built a harmonious model for water rights allocation, and Feng-ping $\mathrm{Wu}$ et al. [13] proposed the harmonious method of allocating basin water rights.

According to the existing literature, despite different perspectives, much research has applied a considerable amount of initial provincial water rights allocation methods in the pursuit of a more scientific and effective water rights allocation plan. However, along with the evolution of the social-economic-ecological complex system, water rights management in China is now facing many new constraints. The first one is that China is implementing the most stringent mechanism of water resources management which contains "three red lines", namely a "red line" for controlling the total water use, a "red line" for improving the water use efficiency and a "red line" for controlling the pollution of water function zones. Initial provincial water rights allocation must meet the new requirements of the water resources management system in China. The second one is that China advocates the construction of an ecological civilization for which the improvement of water quality is an important guarantee. The third one is that China has put forward five concepts for development and policies for poverty alleviation, and how to realize the balanced and efficient use of water with initial provincial water rights allocation really needs further discussion.

For the new scenarios of water resources management presented above, the existing studies of relevant aspects are inadequate as follows:

- Firstly, current models of initial provincial water rights allocation still lack a comprehensive consideration of the key elements, namely the "three red lines"-including total water use, water efficiency, and water quality. Therefore, in contrast to the existing models of initial provincial water rights allocation, one contribution of this paper is to propose new comprehensive insights for the initial provincial water rights allocation method following the benchmark of the all "three red lines" under the new scenarios of the most stringent water resources management in China.

- Secondly, the social-economic-ecological complex system of the provinces is always in the process of dynamic evolution. Most existing allocation methods are limited to analysis of static cross-section data. Seldom do they consider both developing situation of a system and its dynamic evolving trend. Therefore, the other contribution of this paper is to consider initial provincial water rights allocation based on the total water use control as a three-dimensional 
dynamic decision question for time, indicator, and allocation plan. We are concerned not only about the static analysis of the system, but also the dynamic development of the system.

- Thirdly, the existing indicator system studies are inadequate for meeting the new most stringent water resource management requirements. Hence, the third contribution of this paper is that we design an index system of initial provincial water rights allocation by absorbing the concepts of "three red lines" and the idea of coordinated and sharable development of provinces. Based on the designed index system, we set up an initial provincial water rights allocation model with the total water use control by dynamic projection pursuit technique. Furthermore, we tackle the model with a self-adaptive chaotic optimization algorithm to acquire the solutions for province initial water rights allocation, and study the case of Taihu Basin. The outline of the paper can be depicted in Figure 2.

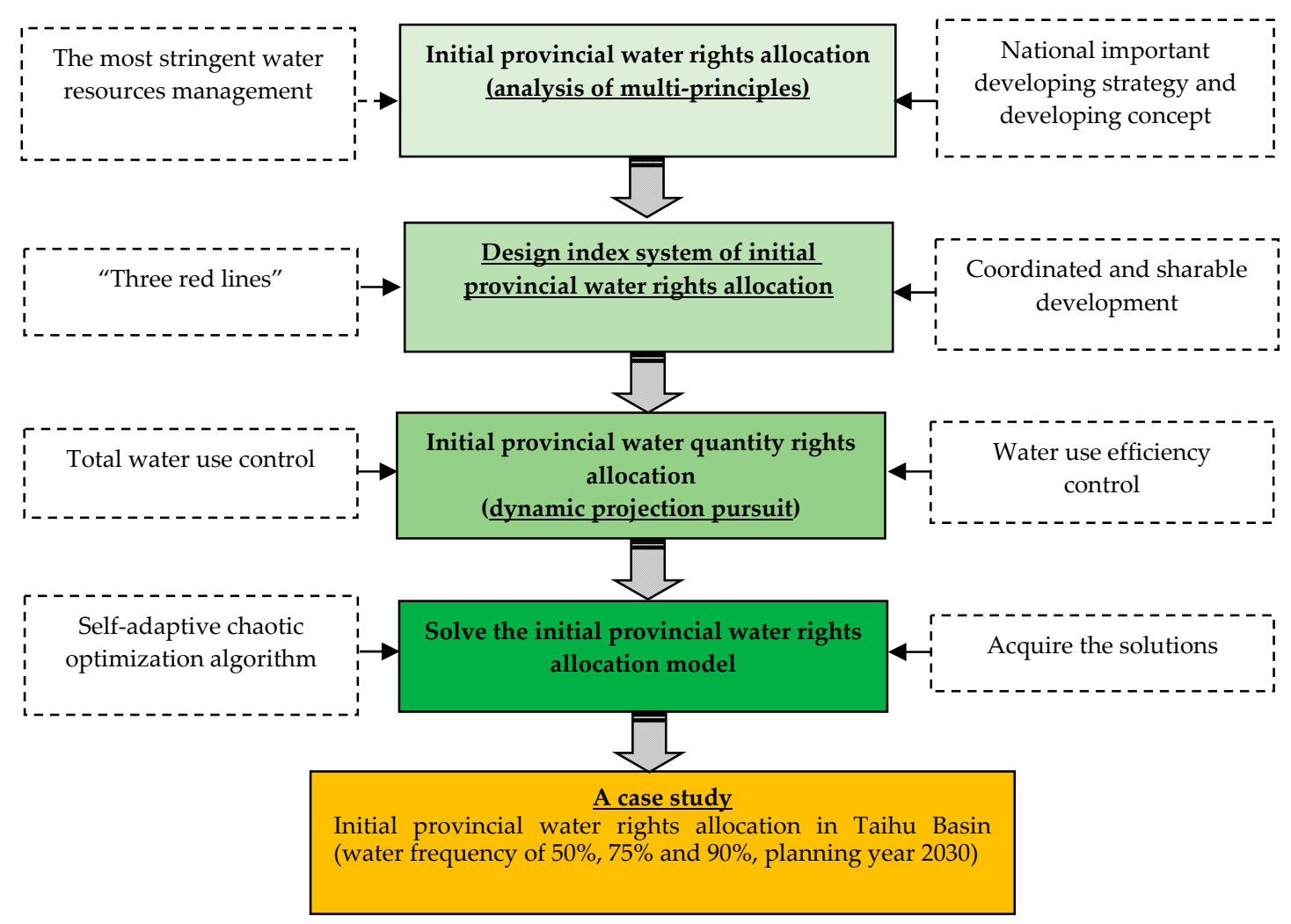

Figure 2. Outline of initial provincial water right allocation based on most stringent water resources management.

The rest of this study is organized as follows. Section 2 designs an index system of initial provincial water rights allocation with multiple principles. Section 3 establishes a dynamic projection pursuit allocation model of initial provincial water rights. Section 4 details a case study of Taihu Basin. Section 5 provides the conclusions.

\section{Design of the Index System}

\subsection{The Principles of Establishing Index System}

The principles of the establishing index system are important to ensure this method and conclusion are accepted by the administration and the public [13]. The existing literature presents different principles of initial provincial water rights allocation. In order to meet the new requirements of the most stringent water resources management in China, we follow the principles of "three red 
lines". Furthermore, we follow the principle of "coordinate development, share the future" to design the indicator system for the initial provincial water rights allocation.

\subsubsection{Principle of Controlling the Total Water Use}

As the key content of the most stringent water resources management system, control gives dual attention to two dimensions of water quantity and quality. The principle of total water use is shown on the foundation of water resources capacity which means a macroscopic control over the water use of basins or provinces. It sets a bearing capacity of water resources within which people can ensure sustainable social and economic development through rational and efficient water use. As the main controlling factor, it aims to protect ecological environment, and also strengthen the constraining force of water resources management and promote the optimal use of water resources.

\subsubsection{Principle of Improving the Water Use Efficiency}

The principle of improving the water use efficiency has water conservation as its main target. It can reflect controlling the process of water saving, in addition, it can reveal the high utilization rate of water resources and lower pollutant discharge, which is a benefit for water quality protection. At a macro level, this red line can control the water total amount of a basin or a province, furthermore, at a micro level, it is the quota management to the total water use of industries, enterprises, and water users, which can directly influence not only the water quantity but also the water quality.

\subsubsection{Principle of Controlling Pollution of Water Function Zones}

The principle of controlling the pollution of water function zones, which is mainly used for limiting the total pollutant discharge, safeguarding the proportion of drinking water sources meeting the required standard, and keeping the ecological base flow for eco-environmental needs. It protects water environment bearing capacity including water quality and water ecology. Furthermore, it restores the damaged water ecology, improves water quality, and decreases the amount of pollutants in the basin.

\subsubsection{Principle of "Coordinate Development, Share the Future"}

The principle of "coordinate development, share the future" leads a profound reform idea in China. At the present stage, initial water rights allocation research should satisfy bearable balanced development of environmental resources between regions, and also should include the idea of coordinated and sharable development. In fact, there is a natural difference in water resources endowment between different provinces including bad geographical location, backward economic development, and a worsening ecological environment. We should give full consideration to the contribution of different provinces for basin water resources management in water pollution control and flood discharging. Moreover, in water rights management, we must ensure coordination and equality within initial provincial water rights allocation and protect the basic rights of disadvantaged groups. Then we are able to implement the poverty-reducing policy and share the achievements of development.

\subsection{Index System Design}

According to the characteristics of initial provincial water rights allocation, combined with the principle for "three red lines" control and absorbing the idea of coordinated and sharable development, considering the representativeness and availability of related data, we designed the index system of initial provincial water rights allocation which is shown in Table 1.

In fact, because of the specificities of water resources, initial provincial water rights allocation proves to be a complicated problem including the aspects of social development, economic growth, 
and the construction of ecological civilization. Consequently, the index system in Table 1 attempts to achieve the following basic aims:

- Coordinate the general interests and the partial interests, so as to maximize the overall satisfaction in a basin.

- Clearly depict, describe, and measure the developing state and development trends in the whole river basin system.

- Equally reflect the requirements of every stakeholder.

Table 1. The index system of initial provincial water rights allocation.

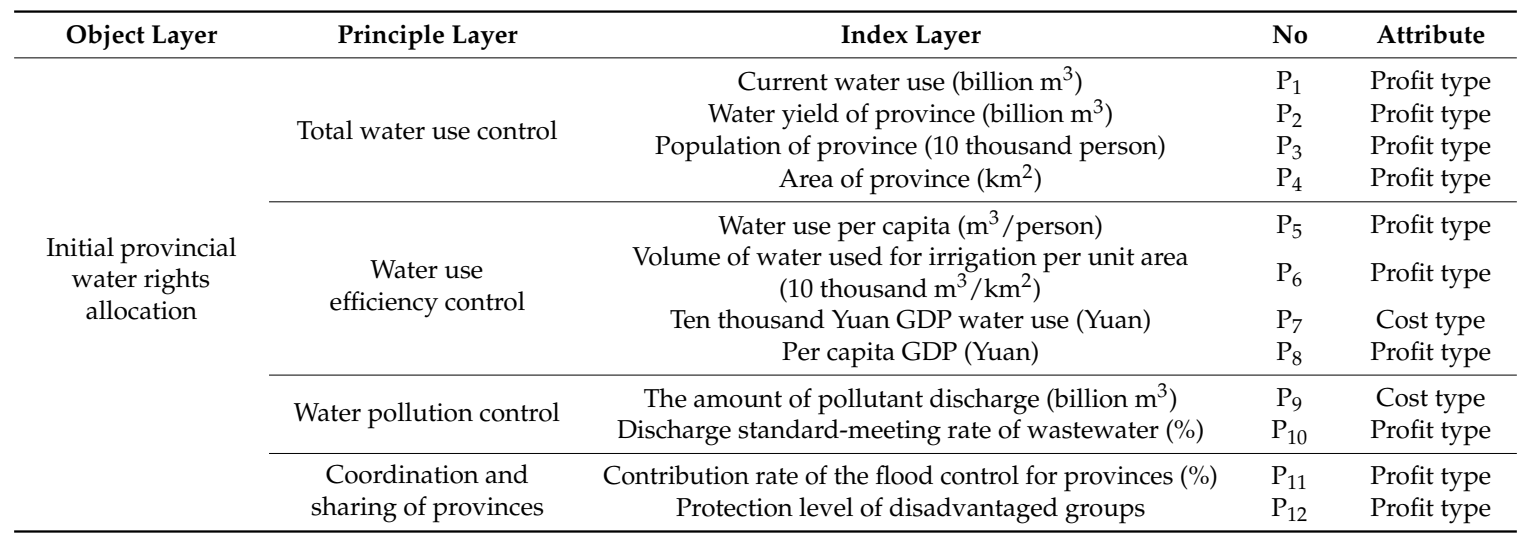

The meaning of indexes can be illustrated as follows: (1) Current water use $\left(\mathrm{P}_{1}\right)$ reflects the current water use situation and also expresses the respect for the provincial different history of water use; (2) Water yield of province $\left(\mathrm{P}_{2}\right)$ is decided by annual average runoff. It represents the respect of priority for local water sources. Specifically, those with more water yields should be given more initial water rights; (3) Population of province $\left(\mathrm{P}_{3}\right)$ reflects people who lives in the same river basin should own the same initial water rights; (4) Provincial area $\left(\mathrm{P}_{4}\right)$ shows province should be given more initial water rights if it has more area; (5) Water use per capita $\left(P_{5}\right)$ is the ratio between provincial current water use and its population; (6) The volume of water used for irrigation per unit area $\left(\mathrm{P}_{6}\right)$ is the ratio between provincial current water use and its irrigation area; (7) Ten thousand Yuan GDP water use $\left(\mathrm{P}_{7}\right)$ reflects water resources use efficiency. A smaller indicator value means higher water resources use efficiency; (8) Per capita GDP $\left(\mathrm{P}_{8}\right)$ is the ratio between provincial GDP and its population which can reflect the general economic development level; (9) The amount of pollutant discharge $\left(\mathrm{P}_{9}\right)$ represents the idea that more provincial pollutant discharge should result in less initial water rights; (10) Discharge standard-meeting rate of wastewater $\left(\mathrm{P}_{10}\right)$ means the water function area with low water quality standard should result in less initial water rights; (11) Contribution rate of the flood control for provinces $\left(\mathrm{P}_{11}\right)$ reflects the ratio between provincial flood discharge and river basin flood discharge. The higher ratio means the higher contribution and they should be assigned more initial water rights, consequently; (12) Protection level of disadvantaged groups $\left(\mathrm{P}_{12}\right)$ reflects the disadvantaged provinces with bad geographical location or a backward economic development level and worsening ecological environment should be effectively protected for the assignment of initial water rights. The protection level of disadvantaged groups $\mathrm{P}_{12}$ can be represented by grades scaling 1-10 [13]. The higher grades of the protection level of the disadvantaged groups mean that more initial water rights should be assigned.

\section{Dynamic Projection Pursuit Allocation Model of Initial Provincial Water Rights}

Initial provincial water rights allocation based on water use control is a three-dimensional dynamic decision making problem for time, index, and allocation plans. Taking full account of the primitive values of indexes which reflect developing situation of allocation system and annual 
increment values of indexes which present its dynamic increment evolving situation, we will adopt dynamic projection pursuit (DPP) technology to acquire the weights of the times and indexes. Furthermore, by calculating the best projection value, we can finally obtain the optimal allocation ratios and plans for the initial provincial water rights. During this process, we choose the dynamic projection pursuit method, because it is different from the existing initial water rights allocation methods. It can reflect the dynamics of data and overcome the difficulties of determining the weights of times and indexes.

\subsection{Basic Data Processing}

(1) $S_{k}$ denotes the province, $k=1,2, \ldots, q ; T_{i}$ denotes the year, $i=1,2, \ldots, n ; P_{j}$ denotes the index, $j=1,2, \ldots, m$.

(2) Let $a_{k i j}$ denote the primitive value of index $P_{j}$ for province $S_{k}$ at year $T_{i}$. The analysis matrix of year $T_{i}$ can be described by Equation (1).

$$
A_{i}=\left(a_{k i j}\right)_{q \times m}
$$

where $k=1,2, \ldots, q ; i=1,2, \ldots, n ; j=1,2, \ldots, m$.

Let $a_{k i j}{ }^{\prime}$ denote the absolute increment value of indexes $P_{j}$ for province $S_{k}$ at year $T_{i}$, which can be written as follows:

$$
a_{k i j}{ }^{\prime}=a_{k i j}-a_{k(i-1) j}
$$

where $i \geq 2$, where $k=1,2, \ldots, q ; i=2, \ldots, n ; j=1,2, \ldots, m$. Thus, we can get the absolute increment value matrix for the initial provincial water rights allocation at year $T_{i}$, which can be presented by Equation (3).

$$
A_{i}^{\prime}=\left(a_{k i j}{ }^{\prime}\right)_{q \times m}
$$

where $k=1,2, \ldots, q ; i=2, \ldots, n ; j=1,2, \ldots, m$.

(3) Adopting the improved efficiency coefficient method to remove dimensions of indexes, then matrix $A_{i}$ and $A_{i}{ }^{\prime}$ are normalized.

Let $b_{k i j}$ denote the non-dimensional value of $a_{k i j}$. When $a_{k i j}$ represents a profit type, $b_{k i j}$ can be obtained by Equation (4).

$$
b_{k i j}=\left\{\left(a_{k i j}-\min _{k} \min _{i} a_{k i j}\right) /\left(\max _{k} \max _{i} a_{k i j}-\min _{k} \min _{i} a_{k i j}\right)\right\} \times 40+60
$$

Moreover, when $a_{k i j}$ represents cost type, $b_{k i j}$ can be obtained by Equation (5).

$$
b_{k i j}=100-\left\{\left(a_{k i j}-\min _{k} \min _{i} a_{k i j}\right) /\left(\max _{k} \max _{i} a_{k i j}-\min _{k} \min _{i} a_{k i j}\right)\right\} \times 40
$$

where $k=1,2, \ldots, q, i=1,2, \ldots, n, j=1,2, \ldots, m . b_{k i j} \in[60,100]$.

Let $c_{k i j}$ denote the non-dimensional value of $a_{k i j}{ }^{\prime}$. When $a_{k i j}{ }^{\prime}$ is a profit type, $c_{k i j}$ can be obtained by Equation (6).

$$
c_{k i j}=\left\{\left(a_{k i j}{ }^{\prime}-\min _{k} \min _{i} a_{k i j}{ }^{\prime}\right) /\left(\max _{k} \max _{i} a_{k i j}{ }^{\prime}-\min _{k} \min _{i} a_{k i j}{ }^{\prime}\right)\right\} \times 40+60
$$

Moreover, when $a_{k i j}{ }^{\prime}$ is cost type, $c_{k i j}$ can be obtained by Equation (7).

$$
c_{k i j}=100-\left\{\left(a_{k i j}{ }^{\prime}-\min _{k} \min _{i} a_{k i j}{ }^{\prime}\right) /\left(\max _{k} \max _{i} a_{k i j}{ }^{\prime}-\min _{k} \min _{i} a_{k i j}{ }^{\prime}\right)\right\} \times 40
$$

where $k=1,2, \ldots, q, i=2, \ldots, n, j=1,2, \ldots, m . c_{k i j} \in[60,100]$.

(4) The normalized matrix $A_{i}$ can be expressed by Equation (8).

$$
B_{i}=\left(b_{k i j}\right)_{q \times m}
$$


where $k=1,2, \ldots, q ; i=1,2, \ldots, n ; j=1,2, \ldots, m$.

Moreover, the normalized matrix $A_{i}{ }^{\prime}$ can be estimated by Equation (9).

$$
C_{i}=\left(c_{k i j}\right)_{q \times m}
$$

where $k=1,2, \ldots, q ; i=2, \ldots, n ; j=1,2, \ldots, m$.

(5) Comprehensively considering $b_{k i j}$ and $c_{k i j}$, the comprehensive index analysis matrix can be expressed by Equation (10).

$$
E_{i}=\left(e_{k i j}\right)_{q \times m}
$$

where $i=2, \ldots, n, j=1,2, \ldots, m$. The element of matrix $E_{i}$ can be measured by Equation (11).

$$
e_{k i j}=\alpha b_{k i j}+\beta c_{k i j}
$$

Here, $e_{k i j}$ means the weighted sum of $b_{k i j}$ and $c_{k i j}, k=1,2, \ldots, q, i=2, \ldots, n, j=1,2, \ldots, m$. Where, $\alpha$ and $\beta$ respectively represent the weights of matrix $B_{i}$ and matrix $C_{i}$. Moreover, $0 \leq \alpha \leq 1$, $0 \leq \beta \leq 1, \alpha+\beta=1$.

When $\alpha>\beta$, it reflects that we give more consideration to the developing situation of indexes themselves; when $\alpha<\beta$, it means the increment or growth situation of indexes should be given more consideration; when $\alpha=\beta=0.5$, it illustrates the situation of the indexes themselves and increment (or growth) situation of indexes are equally important during the allocation for initial water rights.

(6) Transfer $E_{i}$ into the provincial index analysis matrix of initial water rights allocation:

$$
E_{k}=\left(e_{k i j}\right)_{n \times m}
$$

where $k=1,2, \ldots, q$. Then positive ideal matrix $E^{+}$and negative ideal matrix $E^{-}$can be written as follows:

$$
\begin{aligned}
& e_{i j}^{+}=\max \left\{e_{k i j} \mid k=1 \ldots q\right\} \\
& e_{i j}^{-}=\min \left\{e_{k i j} \mid k=1 \ldots q\right\}
\end{aligned}
$$

\subsection{Descriptions of Decision Variables}

After basic data processing, the decision variables of our model can be described as follows: Let $d(k)$ denote the one-dimensional projection value; Let $\theta=\left(\omega_{1}, \ldots \omega_{m}, \lambda_{2}, \ldots \lambda_{n}\right)$ denotes projection direction, where $\omega_{j}$ is the weight of index $P_{j}, \lambda_{i}$ is the weight of year $T_{i}$; Let $d^{*}(k)$ denote the best projection value; Let $\omega_{S_{k}}$ denote the ratio of initial provincial water rights allocation for the province $S_{k}$; Let $w_{S_{k}}$ denote quantity of the initial water rights of the province $S_{k}$.

\subsection{Construct Objective Function of Projection}

The purpose of constructing projection objective function is to decrease high dimensional data into one-dimensional projection data. Each step is presented in the following:

Step 1: Synthesize matrix $E_{k}$ into the one-dimensional projection value $d(k)$ with projection direction $\theta=\left(\omega_{1}, \ldots \omega_{m}, \lambda_{2}, \ldots \lambda_{n}\right)$.

$$
d(k)=\left[\sum_{i=2}^{n} \lambda_{i}\left(\sum_{j=1}^{m} \omega_{j}\left(e_{k i j}-e_{i j}^{-}\right)^{2}\right)\right]^{0.5} /\left\{\left[\sum_{i=2}^{n} \lambda_{i}\left(\sum_{j=1}^{m} \omega_{j}\left(e_{k i j}-e_{i j}^{+}\right)^{2}\right)\right]^{0.5}+\left[\sum_{i=2}^{n} \lambda_{i}\left(\sum_{j=1}^{m} \omega_{j}\left(e_{k i j}-e_{i j}^{-}\right)^{2}\right)\right]^{0.5}\right\}
$$

Furthermore, $d(k)$ is the proximity between the positive and negative ideal solution for province $S_{k}$. 
Step 2: Based on the principle of dispersing the projection value $d(k)$ as far as possible, we can establish projection index function $f(\theta)$ which can be shown in Equation (16).

$$
f(\theta)=s_{d}=\left[\sum_{k=1}^{q}(d(k)-\overline{d(k)})^{2} /(q-1)\right]^{0.5}
$$

where $\overline{d(k)}$ is the mean value of $d(k), k=1,2, \ldots, q$.

Step 3: For getting the best projection value $d(k)$, the maximum value of projection indexes function should be found which can be calculated by Equation (17).

$$
\left\{\begin{array}{l}
\max f(\theta)=s_{d} \\
\text { S.T. }\left\{\begin{array}{l}
c_{1}(\theta)=\sum_{j=1}^{m} \omega_{j}-1=0 \\
c_{2}(\theta)=\sum_{i=2}^{n} \lambda_{i}-1=0, \omega_{j}>0, \lambda_{i}>0
\end{array}\right.
\end{array}\right.
$$

By solving Equation (17), the best projection value $d^{*}(k)$ of the province $S_{k}$ can be measured. The bigger $d^{*}(k)$ means more advantages can be obtained by province $S_{k}$ during the initial water rights allocation.

\subsection{Solutions of Initial Provincial Water Rights Allocation}

Normalize the best projection value $d^{*}(k)$, then the ratio of initial provincial water rights allocation $\omega_{S_{k}}$ which can be presented by Equation (18).

$$
\omega_{S_{k}}=d^{*}(k) / \sum_{k=1}^{q} d^{*}(k)
$$

Set $W$ as the total amount of initial water rights allocated by the river basin. The quantity of initial water rights of the province $S_{k}$ can be calculated by Equation (19).

$$
w_{S_{k}}=W \times \omega_{S_{k}}=W \times\left(d^{*}(k) / \sum_{k=1}^{q} d^{*}(k)\right)
$$

Here, Equation (17) is non-linear programming (NP). In fact, many approaches can solve this kind of nonlinear optimization problem including chaotic optimization algorithm (COA), genetic algorithm (GA), and simulated annealing algorithm [14]. We will choose self-adoptive chaotic optimization algorithm [15] to solve Equation (17).

\section{A Case Study of Taihu Basin}

\subsection{Data Sources}

The administration areas in Taihu Basin mainly include Jiangsu province, Zhejiang province, and Shanghai city. Taihu Basin is one of the most developed and most modernized region in China.

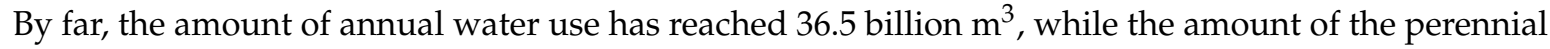
water resources of the basin is only 19.6 billion $\mathrm{m}^{3}$ Therefore, the gap between supply and demand is great.

At present, in Taihu Basin, water shortage, worsening water pollution, and increasing demand of water resources have imposed undue pressure on the carrying capacities of the water resources and water environment. As a result, in order to promote the sustainable development of the basin, it is an inevitable requirement to clarify the initial provincial water rights and implement the allocation plan of Taihu Basin. 
According to the materials of Taihu Basin and Southeast Rivers Water Resources Bulletin [16], some values of indexes for Jiangsu province, Zhejiang province, and Shanghai can be presented respectively as follows (we adopted the annual average values during 2011-2014 as the values of $\mathrm{P}_{2}$, $\mathrm{P}_{4}, \mathrm{P}_{11}$, and $\left.\mathrm{P}_{12}\right)$ :

(1) The index of water yield of province $\mathrm{P}_{2}$ : Jiangsu province is 6.6 billion $\mathrm{m}^{3}$, Zhejiang province is 7.27 billion $\mathrm{m}^{3}$ and Shanghai is 2.01 billion $\mathrm{m}^{3}$.

(2) The area of province $\mathrm{P}_{4}$ : Jiangsu province is $19,399 \mathrm{~km}^{2}$, Zhejiang province is $12,093 \mathrm{~km}^{2}$ and Shanghai is $5178 \mathrm{~km}^{2}$.

(3) The contribution rate of flood control for province $\mathrm{P}_{11}$ : Jiangsu province is $34.5 \%$, Zhejiang province is $15.7 \%$, and Shanghai is $49.8 \%$.

(4) The protection level of disadvantaged groups $\mathrm{P}_{12}$ : Jiangsu province is graded 8 , Zhejiang province is graded 9 , and Shanghai is graded 7.

The other specific relevant data of Taihu Basin during 2011-2014 are summarized in Table 2.

Table 2. Provincial index values of Taihu Basin during 2011-2014.

\begin{tabular}{|c|c|c|c|c|c|c|c|c|c|}
\hline \multirow{2}{*}{ Province } & \multirow{2}{*}{ Year } & \multicolumn{8}{|c|}{ Index Value } \\
\hline & & $\mathbf{P}_{1}$ & $\mathbf{P}_{3}$ & $\mathbf{P}_{5}$ & $\mathbf{P}_{6}$ & $\mathbf{P}_{7}$ & $\mathbf{P}_{8}$ & $\mathbf{P}_{9}$ & $\mathbf{P}_{10}$ \\
\hline \multirow{4}{*}{ Jiangsu } & 2011 & 184.2 & 2939 & 627 & 94.95 & 57 & 8.21 & 29.0 & 28.9 \\
\hline & 2012 & 188.2 & 2960 & 636 & 97.02 & 60 & 8.97 & 29.1 & 13.2 \\
\hline & 2013 & 193.8 & 2985 & 649 & 99.9 & 58 & 9.84 & 29.2 & 26.3 \\
\hline & 2014 & 193.5 & 2996 & 646 & 99.75 & 45 & 10.68 & 28.3 & 19.5 \\
\hline \multirow{4}{*}{ Zhejiang } & 2011 & 51.9 & 1763 & 294 & 42.92 & 43 & 6.54 & 12.1 & 35.7 \\
\hline & 2012 & 51.4 & 1775 & 289 & 42.50 & 39 & 6.97 & 12.1 & 28.6 \\
\hline & 2013 & 52.6 & 1791 & 294 & 43.50 & 36 & 7.53 & 12.6 & 35.7 \\
\hline & 2014 & 50.1 & 1797 & 279 & 41.43 & 32 & 7.98 & 12.9 & 46.2 \\
\hline \multirow{4}{*}{ Shanghai } & 2011 & 91.5 & 1175 & 779 & 176.71 & 77 & 12.01 & 22.6 & 16.7 \\
\hline & 2012 & 109.7 & 1184 & 927 & 211.86 & 62 & 12.53 & 23.1 & 0.00 \\
\hline & 2013 & 117.7 & 1194 & 986 & 227.31 & 64 & 13.44 & 22.9 & 0.00 \\
\hline & 2014 & 99.7 & 1198 & 832 & 192.55 & 53 & 14.47 & 22.9 & 66.7 \\
\hline
\end{tabular}

Notes: Data sources: Taihu Basin and Southeast Rivers Water Resources Bulletin (2011-2014) and Water Quality Bulletin of Taihu Basin and Important Water Function Areas of Southeast Rivers (2011-2014).

\subsection{Calculation of Initial Provincial Water Right Alloction}

Using the initial data of indexes in Table 2, selecting three typical parameter combinations of parameter $\alpha$ and $\beta(\alpha=0.4, \beta=0.6 ; \alpha=0.5, \beta=0.5 ; \alpha=0.6, \beta=0.4)$, according to the initial provincial water dynamic projection pursuit allocation model based on the self-adaptive chaotic algorithm in this paper, we can obtain related solutions by MATLAB 7.01 including the value of optimal projection direction $\theta=\left(\omega_{1}, \ldots \omega_{12}, \lambda_{2}, \lambda_{3}, \lambda_{4}\right)$ and optimal projection value $d^{*}(k)$. Using Equation (18), we can acquire the ratios of the initial provincial water rights allocation which are shown in Table 3.

According to the materials of Taihu Basin and Southeast Rivers Water Resources Bulletin, under the three different water frequencies including 50\%,75\% and $90 \%$, aiming for the planning year 2030, the distributable total amounts of initial water rights in Taihu Basin are 329.2 hundred million $\mathrm{m}^{3}$, 355.4 hundred million $\mathrm{m}^{3}$, and 392.6 hundred million $\mathrm{m}^{3}$ respectively. 
Table 3. Results of initial provincial water rights allocation in Taihu Basin.

\begin{tabular}{|c|c|c|}
\hline \multicolumn{2}{|c|}{ Related Parameter Selecting } & $\begin{array}{l}\text { Initial Population Size } B=200 \text {, Chaotic Iteration } M=100 \text {, } \\
\text { Initial Temperature } T_{0}=100\end{array}$ \\
\hline \multirow{3}{*}{$\begin{array}{l}\alpha=0.6 \\
\beta=0.4\end{array}$} & $\begin{array}{l}\text { Optimal projection direction value } \\
\theta=\left(\omega_{1}, \ldots \omega_{12}, \lambda_{2}, \lambda_{3}, \lambda_{4}\right)\end{array}$ & $\begin{array}{l}(0.1624,0.0741,0.0535,0.0088,0.0778,0.0678,0.0492,0.2125, \\
0.0907,0.0339,0.0808,0.0884,0.1345,0.1841,0.6814)\end{array}$ \\
\hline & Optimal projection value $d^{*}(k), k=1,2,3$ & $\begin{array}{l}\text { Jiangsu } d^{*}(1)=0.5803 ; \text { Zhejiang } d^{*}(2)=0.4298 \\
\text { Shanghai } d^{*}(3)=0.5039\end{array}$ \\
\hline & Ratio of province initial water rights allocation & $\begin{array}{l}\text { Jiangsu } \omega_{S_{1}}=38.33 \% ; \text { Zhejiang } \omega_{S_{2}}=28.39 \% \text {; } \\
\text { Shanghai } \omega_{S_{3}}=33.28 \%\end{array}$ \\
\hline \multirow{3}{*}{$\begin{array}{l}\alpha=0.5 \\
\beta=0.5\end{array}$} & $\begin{array}{l}\text { Optimal projection direction value } \\
\theta=\left(\omega_{1}, \ldots \omega_{12}, \lambda_{2}, \lambda_{3}, \lambda_{4}\right)\end{array}$ & $\begin{array}{l}(0.1147,0.1022,0.0011,0.0473,0.0922,0.0866,0.0310,0.1037, \\
0.0953,0.3102,0.0513,0.0045,0.2074,0.2843,0.5083)\end{array}$ \\
\hline & Optimal projection value $d^{*}(k), k=1,2,3$ & $\begin{array}{l}\text { Jiangsu } d^{*}(1)=0.6045 ; \text { Zhejiang } d^{*}(2)=0.4032 ; \\
\text { Shanghai } d^{*}(3)=0.4794\end{array}$ \\
\hline & Ratio of province initial water rights allocation & $\begin{array}{l}\text { Jiangsu } \omega_{S_{1}}=40.65 \% ; \text { Zhejiang } \omega_{S_{2}}=27.11 \% \text {; } \\
\text { Shanghai } \omega_{S_{3}}=32.24 \%\end{array}$ \\
\hline \multirow{3}{*}{$\begin{array}{l}\alpha=0.4 \\
\beta=0.6\end{array}$} & $\begin{array}{l}\text { Optimal projection direction value } \\
\theta=\left(\omega_{1}, \ldots \omega_{12}, \lambda_{2}, \lambda_{3}, \lambda_{4}\right)\end{array}$ & $\begin{array}{l}(0.0941,0.2306,0.0899,0.0333,0.1185,0.0636,0.0042,0.0724, \\
0.1725,0.0331,0.0145,0.0733,0.1222,0.4322,0.4456)\end{array}$ \\
\hline & Optimal projection value $d^{*}(k), k=1,2,3$ & $\begin{array}{l}\text { Jiangsu } d^{*}(1)=0.6812 ; \text { Zhejiang } d^{*}(2)=0.5772 ; \\
\text { Shanghai } d^{*}(3)=0.3987\end{array}$ \\
\hline & Ratio of initial provincial water rights allocation & $\begin{array}{l}\text { Jiangsu } \omega_{S_{1}}=41.11 \% ; \text { Zhejiang } \omega_{S_{2}}=34.83 \% \text {; } \\
\text { Shanghai } \omega_{S_{3}}=24.06 \%\end{array}$ \\
\hline
\end{tabular}

According to the results of initial provincial water rights allocation in Table 3, we can acquire the larger weight of index $P_{j}$ and year $T_{i}$, and also the ranking results of ratios for provincial initial water rights allocation which can be expressed in Table 4.

Table 4. Ranking results of initial provincial water rights allocation in Taihu Basin, China.

\begin{tabular}{cccc}
\hline $\begin{array}{l}\text { Typical Parameter } \\
\text { Combinations for } \\
\text { Parameter } \alpha \text { and } \beta\end{array}$ & The Larger Weight of Index $\boldsymbol{P}_{j}$ & $\begin{array}{c}\text { The Larger Weight } \\
\text { of Year } \boldsymbol{T}_{\boldsymbol{i}}\end{array}$ & $\begin{array}{c}\text { The Ranking Results of Ratios } \\
\text { for Provincial Initial Water } \\
\text { Rights Allocation }\end{array}$ \\
\hline$\alpha=0.6, \beta=0.4$ & $\begin{array}{c}\text { Current water use }\left(\omega_{1}=0.1624\right) ; \\
\text { Per capita GDP }\left(\omega_{8}=0.2125\right)\end{array}$ & $2014\left(\lambda_{4}=0.6814\right)$ & Jiangsu $\succ$ Shanghai $\succ$ Zhejiang \\
\hline$\alpha=0.5, \beta=0.5$ & $\begin{array}{c}\text { Current water use }\left(\omega_{1}=0.1147\right) ; \\
\text { discharge standard-meeting rate of wastewater } \\
\left(\omega_{10}=0.3102\right)\end{array}$ & $2014\left(\lambda_{4}=0.5083\right) \quad$ Jiangsu Shanghai $\succ$ Zhejiang \\
\hline$\alpha=0.4, \beta=0.6$ & $\begin{array}{c}\text { The water yield of province }\left(\omega_{2}=0.2306\right) ; \\
\text { The amount of pollutant discharge }\left(\omega_{9}=0.1725\right)\end{array}$ & $\begin{array}{c}2013\left(\lambda_{3}=0.4322\right) ; \\
2014\left(\lambda_{4}=0.4456\right)\end{array}$ & Jiangsu $\succ$ Zhejiang $\succ$ Shanghai \\
\hline
\end{tabular}

Consequently, according to the ratio of initial provincial water rights allocation which is shown in Table 3, using Equation (19), we can obtain multiple scenarios of the solutions for initial provincial water rights allocation under three different water frequencies in the planning year 2030 which can be presented in Table 5.

Table 5. Multiple scenarios of solutions for provincial initial water rights allocation in Taihu Basin,

China (water frequencies of 50\%, 75\% and 90\%, planning year 2030, Taihu Basin).

\begin{tabular}{|c|c|c|c|c|c|c|c|c|c|c|}
\hline \multirow{2}{*}{\multicolumn{2}{|c|}{ Solutions of Water Rights Allocation }} & \multirow{2}{*}{\multicolumn{3}{|c|}{$\begin{array}{c}\text { Jiangsu Province } \\
\text { Different Water Frequency }\end{array}$}} & \multirow{2}{*}{\multicolumn{3}{|c|}{$\begin{array}{c}\text { Zhejiang Province } \\
\text { Different Water Frequency }\end{array}$}} & \multirow{2}{*}{\multicolumn{3}{|c|}{$\begin{array}{c}\text { Shanghai } \\
\text { Different Water Frequency }\end{array}$}} \\
\hline & & & & & & & & & & \\
\hline & & \multirow{2}{*}{\begin{tabular}{c|}
$\mathbf{5 0} \%$ \\
126.18
\end{tabular}} & \multirow{2}{*}{$\begin{array}{c}75 \% \\
136.22\end{array}$} & $90 \%$ & \multirow{2}{*}{$\begin{array}{c}\mathbf{5 0 \%} \\
93.45\end{array}$} & \multirow{2}{*}{$\begin{array}{c}75 \% \\
100.89\end{array}$} & $90 \%$ & \multirow{2}{*}{$\begin{array}{c}\mathbf{5 0} \% \\
109.57\end{array}$} & \multirow{2}{*}{\begin{tabular}{c|}
$\mathbf{7 5} \%$ \\
118.29
\end{tabular}} & $90 \%$ \\
\hline Solutions of dynamic & $\alpha=0.6, \beta=0.4$ & & & 150.48 & & & 111.45 & & & 130.67 \\
\hline projection pursuit allocation & $\alpha=0.5, \beta=0.5$ & 133.82 & 144.47 & 159.59 & 89.26 & 96.36 & 106.45 & 106.12 & 114.57 & 126.56 \\
\hline model $\left(100\right.$ million $\left.\mathrm{m}^{3}\right)$ & $\alpha=0.4, \beta=0.6$ & 135.33 & 146.10 & 161.39 & 114.67 & 123.79 & 136.75 & 79.21 & 85.51 & 94.46 \\
\hline
\end{tabular}

\subsection{Analysis of Result}

In Table 4, the empirical results of the larger weight of index $P_{j}$ and year $T_{i}$, and the ranking results of provincial initial water rights allocation can be described as follows: 
- When $\alpha \geq 0.5$, as is clearly indicated in Table 4: (1) According to the larger weight of year $T_{i}$, the ranking results of provincial initial water rights are all mainly influenced by the data in 2014; (2) Considering the larger weight of index $P_{j}$ : (1) when $\alpha>0.5$, current water use $\left(\mathrm{P}_{1}\right)$ and per capita GDP $\left(\mathrm{P}_{8}\right)$, which respectively belong to the principles of the total water use control and water use efficiency, are two important indexes for the ranking results; (2) when $\alpha=0.5$, the current water use $\left(\mathrm{P}_{1}\right)$ and discharge standard-meeting rate of wastewater $\left(\mathrm{P}_{10}\right)$, which respectively belong to the principles of the total water use control and controlling pollution have considerable impacts on the ranking results; (3) When $\alpha>0.5$ and $\alpha=0.5$, these two ranking results show if we are more concerned about the primitive values of indexes themselves, namely in the short term. The developing situation of provinces are given more consideration, Jiangsu Province should obtain the largest ratio of initial provincial water rights allocation all the time, followed by Shanghai and Zhejiang Provinces. Furthermore, from the short-term perspective, the principles of total water use control and water use efficiency should be taken into account. In addition, along with the increasing value of $\beta$, the principle of controlling pollution is vital for the initial water rights allocation.

- When $\beta>0.5$, the empirical results can be expressed as follows: (1) According to the larger weight of year $T_{i}$, the data from 2013 and 2014 are crucial to the ranking results; (2) Based on the larger weight value of index $P_{j}$, the water yield of province $\left(\mathrm{P}_{2}\right)$ and the amount of pollutant discharge $\left(\mathrm{P}_{9}\right)$ which respectively belong to the principles of the total water use control and controlling pollution will mainly influence the allocation results of initial water rights; (3) When $\beta>0.5$, the ranking results show if we give more weight to the annual increment values of indexes, namely in the long term, we give greater consideration to the dynamic increment evolving trend of provinces, Jiangsu Province still acquire the largest ratio of initial provincial water rights allocation, but Zhejiang Province will obtain more ratio than Shanghai. Furthermore, from the long term perspective, the principles of the total water use control and controlling pollution will be considerable for the allocation of the provincial initial water rights.

\section{Conclusions}

Under the new background of the most stringent water resources management in China, an effective and reasonable allocation of initial provincial water rights following the benchmark of the three red lines is the basis and prerequisite for a water rights trade-off market. It is an effective solution to the problem of water scarcity and a significant approach for achieving harmony between economic and social development and available water resources in China. The dynamic projection pursuit allocation method proposed to obtain the multiple scenarios of solutions for initial provincial water rights has met the requirements of controlling the total water use, improving water use efficiency, and controlling pollution of water function zones. Furthermore, it absorbed the idea of coordinated and sharable development. The empirical research of Taihu Basin further verified the feasibility and effectiveness of the model in this paper. The empirical results shown under the different water frequencies of $50 \% 75 \%$ and $90 \%$, for the planning year 2030 , where the developing situation of provinces is given more consideration, Jiangsu Province obtains the most initial water rights, followed by Shanghai City and Zhejiang Province. If we are more concerned about the dynamic increment evolving trend of provinces, Jiangsu Province will acquire the most quantity of initial provincial water rights, but Zhejiang Province should obtain more than Shanghai City. Further research can focus on improving the index system of initial provincial water rights allocation to satisfy the requirements of the most stringent water resources management better.

Acknowledgments: The authors would like to thank the financial support provided by the National Natural Science Foundation of China (Grant No. 71301063; Grant No. 41271537), sponsorship provided by "Jiangsu Overseas Research and Training Program for University Prominent Young and Middle-aged Teachers and Presidents" (2014) and "333" high-caliber talents cultivation project of Jiangsu Province (No. (2013)III-2110). 
Author Contributions: Min Ge designed the research and drafted the manuscript; Feng-Ping Wu conducted the model simulation, reviewed, commented on, and revised the manuscript; Min You collected the data. All authors have read and approved the final manuscript.

Conflicts of Interest: The authors declare no conflict of interest.

\section{References}

1. Coase, R.H. The Problem of Social Cost. J. Law Econom. 1960, 3, 1-44. [CrossRef]

2. Wang, H.; Wang, J.; Qin, D. Research advances and direction on the theory and practice of reasonable water resources allocation. Adv. Water Sci. 2004, 15, 123-128.

3. Wu, D.; Wu, F.; Chen, Y. The bi-level optimization model of the compound system for basin initial water right allocation. Syst. Eng. Theory Pract. 2012, 32, 196-202.

4. Ge, M.; Wu, F.; You, M. A provincial initial water rights incentive allocation model with total pollutant discharge control. Water 2016, 8, 525. [CrossRef]

5. Ralph, W.A. Modeling river-reservoir system management, water allocation, and supply reliability. J. Hydrol. 2005, 300, 100-113.

6. Chen, Y.; Wu, F.; Zhou, Y. Analysis of evolutionary game between strong group and vulnerable group in initial water rights allocation. Soft Sci. 2011, 25, 11-15.

7. Read, L.; Madani, K.; Inanloo, B. Optimality versus stability in water resource allocation. J. Environ. Manag. 2014, 133, 343-354. [CrossRef] [PubMed]

8. Wu, F.; Ge, M. Initial allocation model for water right of the first hierarchy. J. Hohai Univ. (Nat. Sci.) 2005, 33, 216-219.

9. Huang, X.; Shao, D.; Gu, W.; Dai, T. Optimal water resources deployment based on multi-objective chaotic optimization algorithm. J. Hydraul. Eng. 2008, 39, 183-188.

10. Condon, L.E.; Maxwell, R.M. Implementation of a linear optimization water allocation algorithm into a fully integrated physical hydrology model. Adv. Water Resour. 2013, 60, 135-147. [CrossRef]

11. Wu, F.; Ge, M. Method for interactive water right initial allocation based on harmoniousness judgment. J. Hohai Univ. (Nat. Sci.) 2006, 34, 104-107.

12. Wang, Z.J.; Zheng, H.; Wang, X.F. A harmonious water rights allocation model for Shiyang river basin, Gansu province, China. Int. J. Water Resour. Dev. 2009, 25, 355-371.

13. Wu, F.; Chen, Y. Research on the Harmonious Allocation Method of Initial Water Rights in a Basin; China Water Power Press: Beijing, China, 2010.

14. Liu, Z.; Yang, D. Research advances of chaos optimization algorithms for engineering global optimization. Chin. J. Comput. Mech. 2016, 33, 269-286.

15. Wang, S.; Cheng, C.; Wu, X.; Li, B. Application of self-adaptive chaos whole annealing genetic algorithm to optimal operation of hydropower station groups. J. Hydroelectr. Eng. 2014, 33, 63-71.

16. Taihu Basin Authority of Ministry of Water Resources. Taihu Basin and Southeast Rivers Water Resources Bulletin; Taihu Basin Authority of Ministry of Water Resources: Shanghai, China, 2011-2014.

(C) 2017 by the authors; licensee MDPI, Basel, Switzerland. This article is an open access article distributed under the terms and conditions of the Creative Commons Attribution (CC-BY) license (http://creativecommons.org/licenses/by/4.0/). 